Ontogeny in terminal buds of Abies nordmanniana (Pinaceae) characterized by ubiquitin

Veierskov, Bjarke; Rasmussen, Hanne Nina; Eriksen, Brian

Published in:

American Journal of Botany

DOI:

10.3732/ajb.2007314

Publication date:

2008

Document version

Publisher's PDF, also known as Version of record

Citation for published version (APA):

Veierskov, B., Rasmussen, H. N., \& Eriksen, B. (2008). Ontogeny in terminal buds of Abies nordmanniana

(Pinaceae) characterized by ubiquitin. American Journal of Botany, 95(6), 766-771.

https://doi.org/10.3732/ajb.2007314 


\title{
ONTOGENY IN TERMINAL BUDS OF ABIES NORDMANNIANA (Pinaceae) Characterized By UbiQuitin ${ }^{1}$
}

\author{
Bjarke Veierskov,,$^{2,4}$ Hanne N. Rasmussen, ${ }^{3}$ and Brian Eriksen ${ }^{2}$ \\ ${ }^{2}$ University of Copenhagen, Department of Plant Biology, Thorvaldsensvej 40, 1871 Frederiksberg C, Denmark; and ${ }^{3}$ University \\ of Copenhagen, Forest \& Landscape, Hoersholm Kongevej 11, 2970 Hoersholm, Denmark
}

\begin{abstract}
Meristematic activity in the bud meristem of Abies nordmanniana was visualized by ubiquitin immunohistochemical localization from before bud break and throughout shoot expansion. Ubiquitin was detected in meristematic cells either in the cytosol or nucleus, or both, depending on tissue type and developmental stage. During winter dormancy, ubiquitin was only observed in the protodermal/hypodermal layers, but at bud break in mid May, the signal expanded to the entire shoot tip. At the end of May, a clear zonation in ubiquitin localization appeared that lasted about one month. Throughout this period, ubiquitin was barely detectable in a central group of cells that might indicate an organizing center with stem cells. At the end of June, coinciding with the transition from scale leaf to needle primordia production, ubiquitin again was more prevalent in the peripheral cell layers. During shoot expansion, a strong ubiquitin signal developed in the axil of all needles. Most of these signals later disappeared, except for those few axils where buds actually developed. A strong ubiquitin signal was also observed in cells lining the young resin ducts. Our data showed that ubiquitin may be used as a marker for metabolic activity associated with seasonal development in the apical meristem.
\end{abstract}

Key words: apical shoot meristem; bud development; gymnosperm; immunohistochemistry; resin ducts.

The shoot apical meristem consists of mitotic and postmitotic cells that differ in metabolic activity, fate, and gene expression depending on their position (Reddy and Meyerowitz, 2005; Wyrzykowska et al., 2006). Most information regarding differentiation and development in meristems has been gained by anatomical investigations, and meristematic activity has traditionally been determined by the presence of mitotic activity (Sachs et al., 1959; Jacqmard et al., 2003). Molecular markers of meristematic activity are now widely used, especially in Arabidopsis (Schrader et al., 2004), but they are often of limited use in other species.

Metabolic activity in the meristem is characterized by a high turnover of many proteins, for which ubiquitin is a key regulator (Smalle and Vierstra, 2004). The ubiquitin-dependent proteolytic pathway is conserved in all eukaryotes and is required in plants for cellular organization in the shoot apical meristem (Sonoda et al., 2007), such as the cell cycle (Francis, 2007), cell proliferation and differentiation (del Pozo et al., 2006). Besides regulating the cell cycle in complex meristems, ubiquitin also regulates basic metabolism in the cytosol (Walling, 2006). Ubiquitin conjugates to a lysine residue on a range of proteins, thereby targeting them for degradation by the proteasome (Ingvardsen et al., 2001; Smalle and Vierstra, 2004). The shoot apical meristem of sunflowers contained a uniformly high level of ubiquitin, mainly located in the nuclei, whereas the signal was primarily located in the cytosol in the root apical meristem

\footnotetext{
${ }^{1}$ Manuscript received 10 October 2007; revision accepted 13 March 2008.

Plants were kindly donated by Gl. Kirstineberg Nursery, DK 4800 Denmark.

${ }^{4}$ Author for correspondence (e-mail: bv@life.ku.dk), phone: +45 35333328, fax: +45353383365
}

doi:10.3732/ajb.2007314
(Ingvardsen et al., 2001). Although present in all plant cells, ubiquitin is much higher in cells with high metabolic activity and may thus be a suitable marker for identifying alterations in metabolic activity.

Before winter dormancy, the buds of many gymnosperms, such as species of Picea and Abies, contain primordial shoots at an advanced stage of organogenesis. In spring, the preformed shoot from the overwintering bud expands, and the apical meristem resumes activity, producing next year's shoot initial. The first leafy structures are generally bud scales (cataphylls), formed in early summer, followed by production of foliage leaf primordia (needles) until bud dormancy is induced in the fall (Parke, 1959; Soukupova et al., 2002). Angiosperms generally have buds in the axils of their leaves (Garrison, 1955), whereas in gymnosperms such as the conifers, needle axils have often been classified as empty without necessarily being so (Henry, 1846; Fink, 1984).

In this paper we localized ubiquitin to test its usefulness in visualizing cellular activity during development in a complex meristem in a histologically well-described system such as the conifer bud. Abies nordmanniana Spach. was chosen because its growth pattern is regular and modular, enabling us to consecutively excise buds with well-defined, homologous positions and fates.

\section{MATERIALS AND METHODS}

Plant material and growing conditions-Six-years-old saplings of A. nordmanniana were grown in 10 liter containers under nursery conditions $(\mathrm{Gl}$ Kirstineberg Nursery, Nykøbing F, Denmark, $54^{\circ} 77^{\prime} \mathrm{N}, 11^{\circ} 87^{\prime} \mathrm{E}$ ) as described by Veierskov et al. (2007). A morphologically uniform set of trees with five whorl branches at the top was selected. The terminal bud on the branches in the uppermost whorl was consistently excised at intervals from before bud break until the next season's dormancy. No tree was sampled more than once, and at each sampling time 10 trees were randomly chosen. 
Immunohistochemistry-Immunohistochemistry was performed as described by Ingvardsen et al. (2001). Tissue samples were fixed in Histochoice (Sigma, Copenhagen, Denmark), and after dehydration, the tissue samples were embedded in paraffin (Paraplast Plus, Sigma). Longitudinal or cross sections ( $7 \mu \mathrm{m}$ thick) were cut and mounted on glass slides and deparaffinized. Each section was treated with $8 \mu \mathrm{L}$ of primary antibody (antiubiquitin antibody DAKO, Copenhagen Denmark), then with EnVision (DAKO) and DAB+ (diaminobenzidine tetrahydrochloride) chromogenic substrate (DAKO), which yielded a visible brown color. After washing with water, the sections were counterstained with toluidine blue. To check for nonspecific staining, we replaced the primary antibody with nonimmune rabbit IgG; and observed no background signal (Fig. 1). Some sections were stained with iodine solution to detect starch $(0.2 \%$ iodine in $2 \%$ potassium iodide solution; Bailey and Whelan [1961]). A Zeiss Photomicroscope 2 with analogue videocamera (Sony, Tokyo, Japan) was used.

\section{RESULTS AND DISCUSSION}

Before bud break, ubiquitin was only detectable at the extreme surface of the meristematic dome, i.e., the protodermis and about 1-2 hypodermal layers (Fig. 2). In longitudinal sections, these cells appeared short compared with their transverse dimension. The nuclei were large with little or no ubiquitin, suggesting low activity, whereas the cytosol clearly contained ubiquitin (Fig. 2), presumably involved in basic metabolism as observed in sunflower (Ingvardsen and Veierskov, 2001). Under the surface layers, there was an irregular central group of cells, distinguishable by very thin walls and large nuclei. Below them, and probably originating as their derivatives, were cell files of the pith parenchyma (Fig. 2), in agreement with patterns in Abies concolor (Parke, 1959).

One week later, after bud break, the shoots were fully emerged from the cataphylls (bud scales), and the number of cells in the shoot tip with detectable levels of ubiquitin had dramatically increased (Fig. 3). Ubiquitin was found in both the surface layers and central cells with similar intensity. The surface cells were characterized by frequent anticlinal divisions, small cell size, and a large nucleus. The central cells divided both periclinally and anticlinally. Ubiquitin was predominantly found in the nuclei (Fig. 3, inset). In a diffuse transitional region toward the pith meristem, ubiquitin was sporadically detected in some cells. Ubiquitin was high in the newly forming cataphylls (Fig. 3).

The lack of clear zonation at this stage could be attributed to vigorous growth of the meristem. Areas with cells undergoing mitosis coincided with areas staining for ubiquitin, clearly demonstrating the role of mitosis during expansion of the preformed shoot. The ubiquitin localization and intensity of detection supports the essential role of ubiquitin in regulating meristematic activity (Martinez et al., 1992; Kondorosi et al., 2005; Francis 2007), hormone signaling (Bishopp et al., 2006) and transcription signals (del Pozo et al., 2006). After c. 3 wk of growth (early June), the distribution of ubiquitin changed greatly, to a pattern that persisted about one month: The epidermis and about four cell layers beneath it retained a very stong ubiquitin signal, which was now more evenly distributed between nuclei and cytosol (Fig. 4, inset A). Meanwhile, a central group of cells contained just barely detectable levels of ubiquitin (Fig. 4, inset B). Proximal to this cell group, several cell layers of the young pith meristem and cortex had a medium strong ubiquitin signal (Fig. 4, inset C). During this 1-mo period, the ubiquitin gradually became concentrated within the pith. The central location of the ubiquitin-poor cell group implies that it probably includes a putative

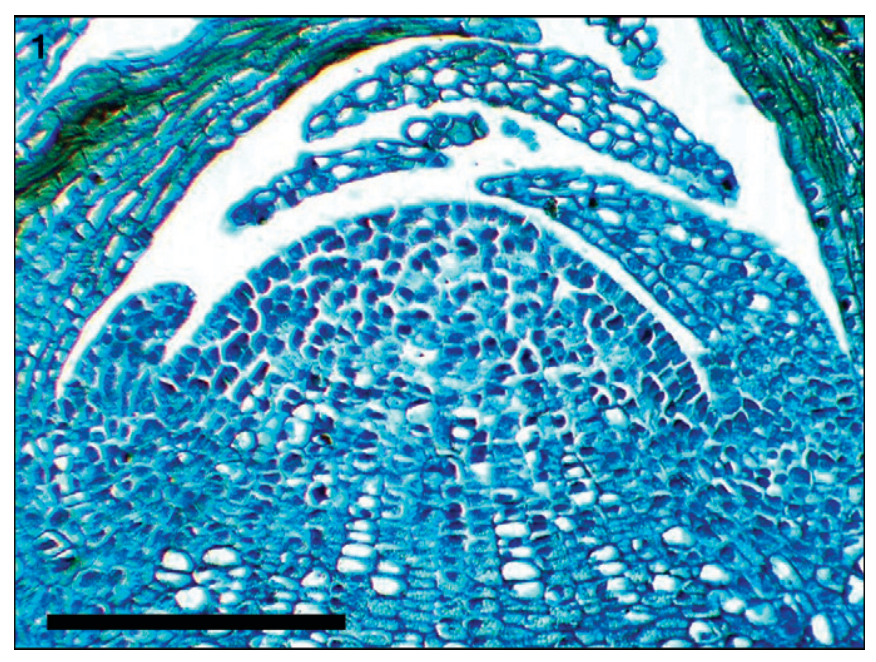

Fig. 1. Light micrograph of negative control for ubiquitin staining in shoot apex of Abies nordmanniana at $11 \mathrm{~d}$ after bud break. This longitudinal section was treated in preimmune serum and counterstained with toluidine blue. Bar $=100 \mu \mathrm{m}$.

meristem organizing center, as described by Schoof et al. (2000). Initials to stem cells divide very slowly, and they are normally difficult to distinguish from surrounding meristematic cells.

In early/mid July shoot expansion slowed, and the shoot apical meristem organogenesis changed from scale leaves to needle production (Fig. 5). A very strong ubiquitin signal was now observed in the region where the new needles were initiated, as well as in the developing primordia. Distal to the needle primordia, the ubiquitin signal was high and uniform within the apical meristem cells, whereas in the needle primordia it was mainly located in the cytosol. This observation supports that meristematic activity continues in the shoot tip and that the needles are retained in a primordial stage.

During early shoot expansion in A. nordmanniana, we observed ubiquitin staining in the superficial stem tissues above every young needle (Fig. 6). In conifers, the needles are traditionally classified as naked (Henry, 1846) although this may only appear so in some conifers (Fink, 1984). The observed ubiquitin signal suggests that axillary buds were initiated, but the signal transduction pathway was terminated very early in the process, causing the ubiquitin signal to disappear before any organogenesis (Fig. 6, inset A). In a few cases, however, buds actually developed (Fig. 6, inset B), primarily close to the apical meristem. Several observations reveal the potential for additional axillary meristems: Both shoot wounding (Burrows, 1989) and bud removal (Rasmussen et al., 2003) may increase axillary bud set experimentally, and a presumed natural mutation of $A$. nordmanniana occurs that causes bud set above each needle (our unpublished observation).

The cortex of the expanding shoot consisted of compact parenchyma cells among which multicellular resin ducts developed (RD). Parenchyma cells were largely without detectable ubiquitin and with a high density of amyloplasts (Figs. 7 and 8). Cells lining the resin ducts were similar in shape and size, but expressed a strong signal for ubiquitin (Fig. 7) and were devoid of amyloplasts (Fig. 8). Ubiquitin was mainly found in the nucleus. The strong ubiquitin signal in the cells lining the resin ducts is consistent with the findings that methyl jasmonate 


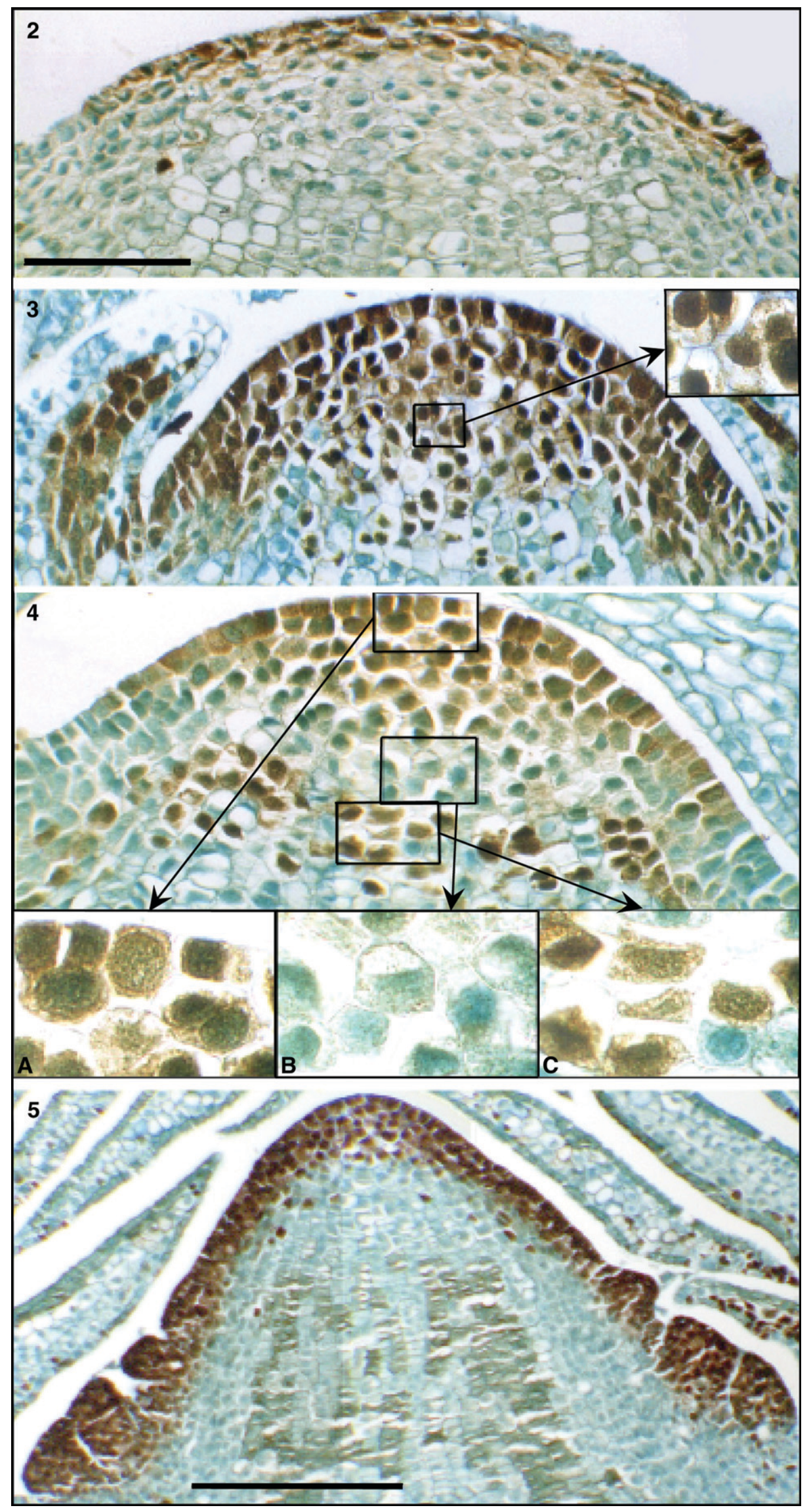




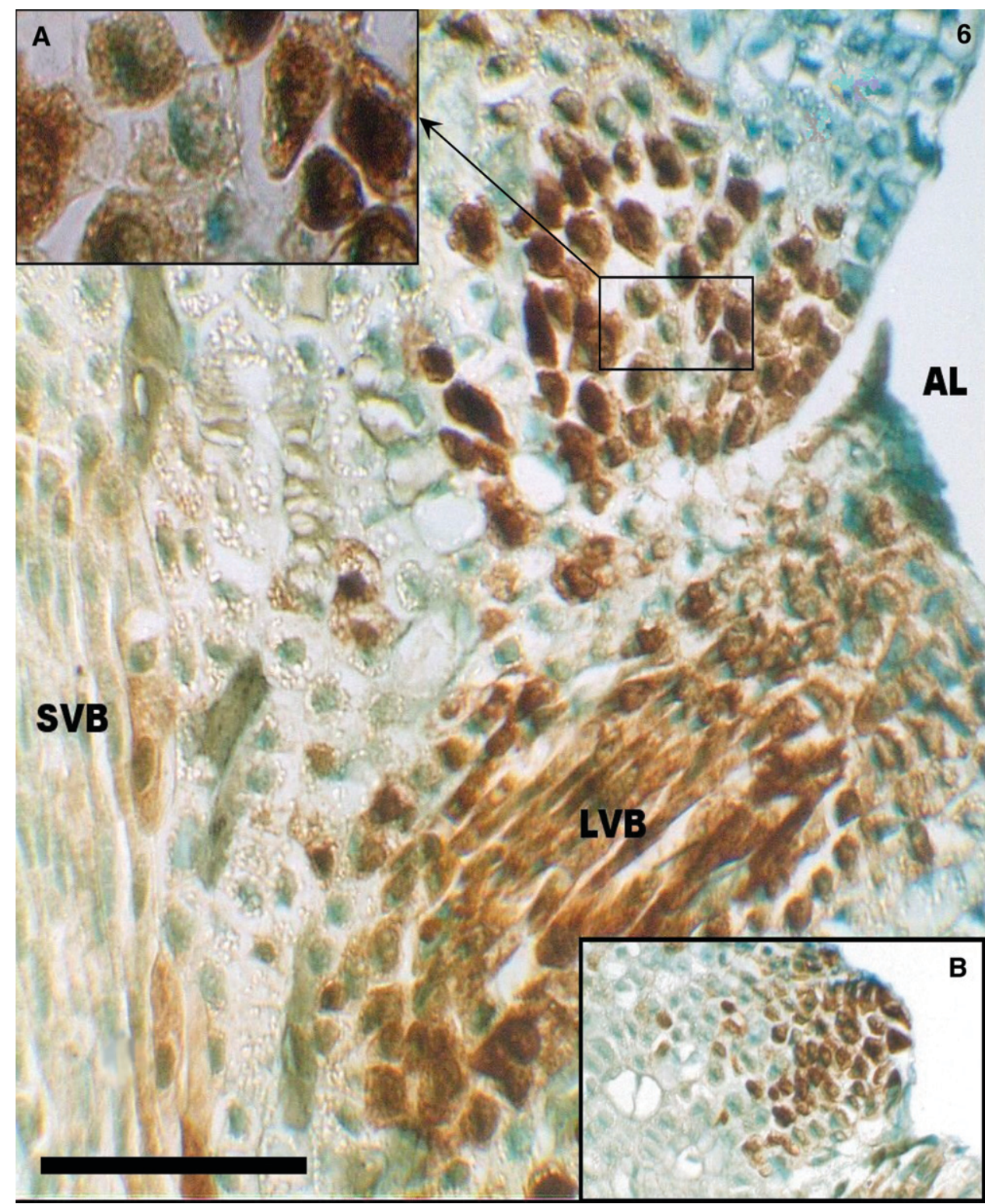

Fig. 6. Light micrographs of longitudinal sections of expanding young shoot of Abies nordmanniana at $3 \mathrm{~d}$ after bud break. Shoot vascular bundle (SVB) of the central cylinder and a vascular leaf trace (LVB) leading to an excised needle (AL). Above the LVB, a group of cells with distinct ubiquitin staining is interpreted as a primordial axillary bud. Inset A, in the central part of the cell group, the ubiquitin signal has faded; inset B, increased ubiquitin signal and initial bud differentiation in a bud producing axil. Bar $=100 \mu \mathrm{m}$.

induces expression of terpenoid synthase and terpenoid accumulation in Norway spruce (Martin et al., 2002; Fäldt et al., 2003) and that ubiquitin-dependent proteolysis is essential for the methyl-jasmonate signaling pathway (Ren et al., 2005).

Conclusions - By localizing ubiquitin, we clearly visualized ontogeny in the apical bud and the development of a zonation when meristematic activity is strongest in the apical meristem. The apparently ubiquitin-free zone between 3 and 7 wk after bud break is suggestive of an organizing center. By localizing ubiquitin, we also demonstrated that the initial stages of axillary bud development occurred for all needles. The localization of ubiquitin in cells can thus be a very efficient approach to describing developing tissues.

Figs. 2-5. Immunohistochemical localization of ubiquitin (brown staining) of shoot apex of Abies nordmanniana. Longitudinal sections were treated

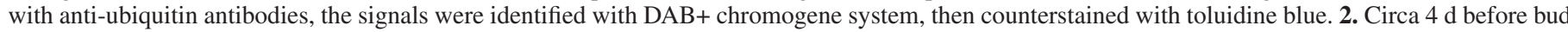

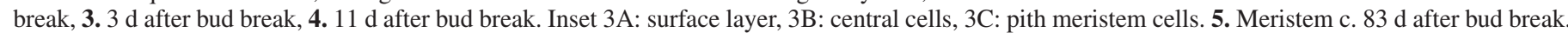
Bars: Fig. 2 (Figs. 3, 4 also), $100 \mu \mathrm{m}$; Fig. 5, $250 \mu \mathrm{m}$. 

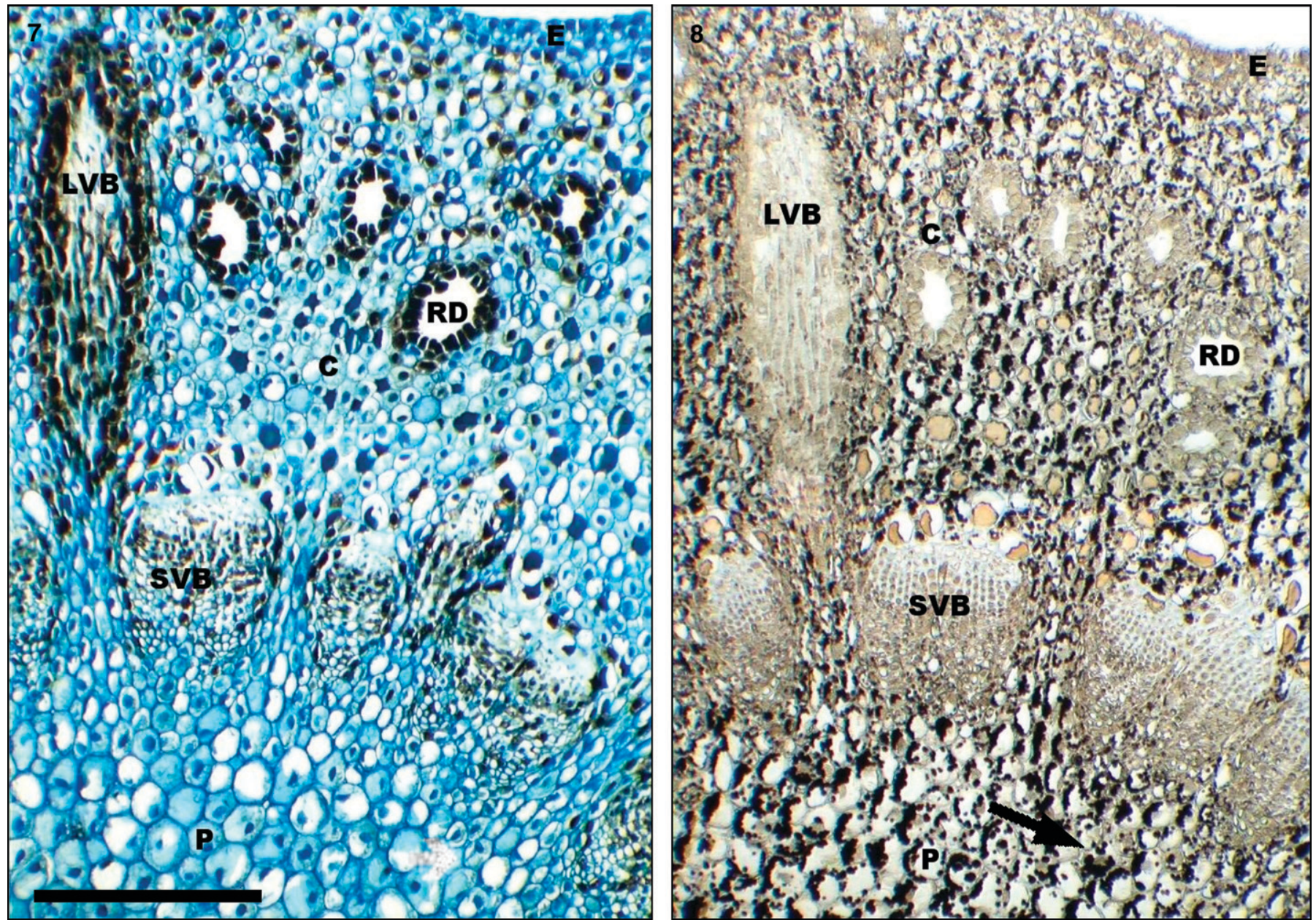

Figs. 7, 8. Light micrographs of adjacent cross sections of expanding shoot of Abies nordmanniana $3 \mathrm{~d}$ after bud break. 7. Ubiquitin stained, counterstained with toluidine blue. 8. Starch detected with iodine (dark bluish staining). Arrow is directed against gravitation. LVB, leaf vascular bundle (negative starch, positive ubiquitin); SVB: shoot vascular bundle (negative starch, positive ubiquitin); RD: resin duct (negative starch, positive ubiquitin); E: epidermis (negative starch, negative ubiquitin); C: cortex (positive starch, negative ubiquitin); P: pith (positive starch, negative ubiquitin). Bar (Fig. 8 also) $=100 \mu \mathrm{m}$.

\section{LITERATURE CITED}

Bailey, J. M., and W. J. Whelan. 1961. Physical properties of starch. 1. Relationship between iodine stain and chain length. The Journal of Biological Chemistry 236: 969-973.

Bishopp, A., A. P. Mahonen, AND Y. Helariutta. 2006. Signs of change: Hormone receptors that regulate plant development. Development 133: $1857-1869$.

Burrows, G. E. 1989. Developmental anatomy of axillary meristems of Araucaria cunninghamii released from apical dominance following shoot apex decapitation in vitro and in vivo. Botanical Gazette (Chicago, Ill) 150: 369-377.

del Pozo, J. C., S. Az-Trivino, N. Cisneros, and C. Gutierrez. 2006. The balance between cell division and endoreplication depends on E2FC-DPB, transcription factors regulated by the ubiquitinSCF ${ }^{\text {SKP2A }}$ pathway in Arabidopsis. Plant Cell 18: 2224-2235.

Fäldt, J., D. Martin, B. Miller, S. Rawat, and J. Bohlmann. 2003. Traumatic resin defense in Norway spruce (Picea abies) Methyl jasmonate-induced terpene synthase gene expression, and cDNA cloning and functional characterization of (+)-3-carene synthase. Plant Molecular Biology 51: 119-133.
FINK, S. 1984. Some cases of delayed or induced development of axillary buds from persisting detached meristems in conifers. American Journal of Botany 71: 44-51.

Francis, D. 2007. The plant cell cycle-15 years on. New Phytologist 174: $261-278$

GARRISON, R. 1955. Studies in the development of axillary buds. American Journal of Botany 42: 257-266.

HENRY, A. 1846. Knopenbilder, ein Beitrag zur der Verzweigungsart der Pflanzen. Nova Acta-Kaiserlich Leopoldinisch-Carolinische Deutsche Akadamie der Naturforscher 22: 171-342.

IngVARDSEN, C., AND B. VeIERSKOV. 2001. Ubiquitin- and proteasomedependent proteolysis in plants. Physiologia Plantarum 112: 451-459.

IngVardsen, C., B. Veierskov, AND P. A. Joshi. 2001. Immunohistochemical localisation of ubiquitin and the proteasome in sunflower (Helianthus annuus cv. Giganteus). Planta 213: 333-341.

JaCQMard, A., I. Gadisseur, AND G. Bernier. 2003. Cell division and morphological changes in the shoot apex of Arabidopsis thaliana during floral transition. Annals of Botany 91: 571-576.

Kondorosi, E., M. Redondo-NiETo, And A. Kondorosi. 2005. Ubiquitinmediated proteolysis. To be in the right place at the right moment during nodule development. Plant Physiology 137: 1197-1204. 
Martin, D., D. Tholl, J. Gershenzon, and J. Bohlmann. 2002. Methyl jasmonate induces traumatic resin ducts, terpenoid resin biosynthesis, and terpenoid accumulation in developing xylem of Norway spruce stems. Plant Physiology 129: 1003-1018.

Martinez, M. C., J. E. Jorgensen, M. A. Lawton, C. J. Lamb, and P. W. Doerner. 1992. Spatial pattern of cdc2 expression in relation to meristem activity and cell-proliferation during plant development. Proceedings of the National Academy of Sciences, USA 89: 7360-7364.

PARKe, R. V. 1959. Growth periodicity and the shoot tip of Abies concolor. American Journal of Botany 46: 110-118.

Rasmussen, H. N., S. Soerensen, and L. Andersen. 2003. Bud set in Abies nordmanniana Spach. influenced by bud and branch manipulations. Trees-Structure and Function 17: 510-514.

Reddy, G. V., ANd E. M. Meyerowitz. 2005. Stem-cell homeostasis and growth dynamics can be uncoupled in the Arabidopsis shoot apex. Science 310: 663-667.

Ren, C. M., J. W. Pan, W. Peng, P. Genschik, L. Hobbie, H. Hellmann, M. Estelle, B. Gao, J. R. Peng, C. Q. Sun, and D. X. Xie. 2005. Point mutations in Arabidopsis Cullinl reveal its essential role in jasmonate response. Plant Journal 42: 514-524.

SAChS, R. M., C. F. BRETZ, AND A. LANG. 1959. Shoot histogenesis-The early effects of gibberellin upon stem elongation in 2 rosette plants. American Journal of Botany 46: 376-384.

Schoof, H., M. Lenhard, A. Haecker, K. F. X. Mayer, G. Jürgens, AND T. LaUX. 2000. The stem cell population of Arabidopsis shoot meristems is maintained by a regulatory loop between the CLAVATA and WUSCHEL genes. Cell 100: 635-644.

Schrader, J., J. Nilsson, E. Mellerowicz, A. Berglund, P. Nilsson, M. Hertzberg, and G. SAndberg. 2004. A high-resolution transcript profile across the wood-forming meristem of poplar identifies potential regulators of cambial stem cell identity. Plant Cell 16: 2278-2292.

Smalle, J., and R. D. Vierstra. 2004. The ubiquitin 26S proteasome proteolytic pathway. Annual Review of Plant Biology 55: 555-590.

Sonoda, Y., S. G. Yao, K. Sako, T. Sato, W. Kato, M. Ohto, T. IchiKawa, M. Matsui, J. Yamaguchi, and A. IKeda. 2007. SHA1, a novel RING finger protein, functions in shoot apical meristem maintenance in Arabidopsis. Plant Journal 50: 586-596.

Soukupova, J., J. Albrechtova, H. Svobodova, and J. Opatrna. 2002. Anatomical and histochemical changes of Norway spruce buds induced by simulated acid rain. Biologia Plantarum 45: 77-84.

Veierskov, B., H. N. Rasmussen, B. Eriksen, AND J. Hansen-Moller. 2007. Plagiotropism and auxin in Abies nordmanniana. Tree Physiology 27: 149-153.

WALLING, L. L. 2006. Recycling or regulation? The role of aminoterminal modifying enzymes. Current Opinion in Plant Biology 9: 227-233.

Wyrzykowska, J., M. Schorderet, S. Pien, W. Gruissem, and A. J. FLEMING. 2006. Induction of differentiation in the shoot apical meristem by transient overexpression of a retinoblastoma-related protein. Plant Physiology 141: 1338-1348. 